\title{
Retraction Note to: Total knee arthroplasty performed with either a mini-subvastus or a standard approach: a prospective randomized controlled study with a minimum follow-up of 2 years
}

\author{
Zhen $\mathrm{Lai}^{1} \cdot$ ShiYuan $\mathrm{Shi}^{1} \cdot$ Jun Fei $^{1} \cdot$ Wei Wei ${ }^{1}$
}

Published online: 21 March 2015

(C) Springer-Verlag Berlin Heidelberg 2015

\section{Retraction to: Arch Orthop Trauma Surg (2014) 134:1155-1162 \\ DOI 10.1007/s00402-014-1963-2}

Archives of Orthopaedic and Trauma Surgery, SpringerVerlag Berlin Heidelberg 2014. This paper, published in Volume 134, Issue 8, pages 1155-1162, DOI 10.1007/ s00402-014-1963-2, has been formally withdrawn by the two corresponding authors on ethical grounds because the article contains extensive and repeated instances of plagiarism. Archives of Orthopaedic and Trauma Surgery treats all identified evidence of plagiarism in the published articles most seriously. It is unfortunate that this misconduct was not detected before going to press. The authors apologize to the Editors and readers as well as the authors of the original article.

The online version of the original article can be found under doi:10.1007/s00402-014-1963-2.

Zhen Lai

laizhen76@163.com

$₫$ ShiYuan Shi

hzhhyiyuanguke@163.com

1 Department of Orthopaedics Surgery, Red Cross Hospital in Hangzhou, No. 208, East Ring Road, Hangzhou 310003, Zhejiang Province, People's Republic of China 